\title{
De los guetos a la territorialización. Urbanismo, exclusión y relaciones humanas en las ciudades modernas
}

\author{
Graciela Victoria Franco Martínez ${ }^{1}$
}

\begin{abstract}
Resumen
La configuración de las ciudades, en determinado tiempo y espacio, suele hablar de la sociedad y la cultura que allí se desarrolla. La arquitectura de la ciudad refleja no sólo las necesidades de los seres humanos que la habitan, sino también la manera como se establecen las relaciones sociales. A partir de una mirada al desarrollo de la ciudad moderna, se evidencia la paradoja de los guetos que se afianzan justamente cuando se presentan mayores entrecruzamientos. Así, la configuración de las ciudades y los espacios del hombre moderno, sufren un proceso de des-territorialización y una posterior territorialización, que se demuestra, ya no en el gueto medieval, sino en ciertas manifestaciones culturales, que dan cuenta de esa gran paradoja.
\end{abstract}

Palabras clave: ciudad, guetos, representación, territorios, multiculturalidad, entrecruzamientos. 


\title{
From the ghettos to territorialisation. Urbanism, exclusion and human relations in modern cities
}

\begin{abstract}
The configuration of cities, in particular time and space, often speaks about culture and society that develop there. The architecture of cities reflects not only the needs of human beings that inhabit them, but also how social relations are established. With the development of modern city, it is evident the paradox of the strengthen of ghettos just as crossovers occurs. Thus, the configuration of cities and spaces of Modernity, go through a process of deterritorialization and a subsequent territorialization, demonstrated, not by the way of medieval ghettos, but in some cultural events, that account for this great paradox.
\end{abstract}

Keywords: city, ghettos, representation, territories, multiculturalism, crosslinks.

\begin{abstract}
A veces la ciudad se convierte en un lugar completamente distinto. Los colores de las calles que a uno le hacen sentirse en casa desaparecen de repente, [...]. Todos los parques se transforman en un momento en eriales fangosos e insípidos, las plazas cubiertas de postes eléctricos y paneles publicitarios en fríos espacios de cemento y la ciudad en un lugar tan completamente vacío como mi alma.
\end{abstract}

Pamuk (2006).

La cita con la que iniciamos este texto corresponde a Estambul, la hermosa obra autobiográfica de Orhan Pamuk, que es también la biografía de la ciudad. A lo largo de toda la narración, el escritor turco demuestra la imposibilidad de salir del círculo de mutua afectación de los individuos y los lugares que habitan. La arquitectura y la planificación de las ciudades pueden dar cuenta de los procesos de las culturas que las habitan y, asimismo, sus habitantes van moldeando las ciudades, como un gran artista anónimo que lleva dentro de sí la multiplicidad, las contradicciones, las tensiones y las particularidades que caracterizan a las culturas. El símil de la sociedad como un gran artista no es gratuito, según el semiólogo ruso G. A. Nedoshivin las relaciones estéticas del hombre con su realidad encuentran en el arte «su forma de expresión más alta» (1970: 137). La 
arquitectura de las ciudades no escapa a esta condición de forma «más alta» de expresión humana, pues partimos del hecho, indiscutible a nuestro juicio, de que la arquitectura es arte.

Heidegger nos ofrece una reflexión muy profunda, que conduce a la idea de la edificación como poesía y esta a la vez, como un acto creativo que rebasa la composición meramente literaria. Sostiene el filósofo alemán que «la poesía es el nombrar fundacional del ser y de la esencia de todas las cosas» (1983: 63). Es así como la poesía es acto creativo, pues crea, construye. Posteriormente, en su conocida obra Filosofía, ciencia y técnica, Heidegger asocia el construir con el habitar, claramente dice que «construir es propiamente habitar» y «habitar es el modo como son los mortales sobre la Tierra» (Heidegger, 1997: 203). Escapa, por supuesto, a nuestras posibilidades y pretensiones ahondar y extendernos en tan interesantes reflexiones, sin embargo, apoyan éstas en buena medida la idea de la interrelación entre los hombres y el espacio que habitan y construyen, o que habitan-construyen, para seguir la idea de Heidegger.

Nuestra propuesta es entonces una aproximación a algunas manifestaciones artísticas, principalmente en la arquitectura, de las ciudades a lo largo de la historia moderna de Occidente, que dan cuenta a la vez de los procesos sociales de las comunidades que las habitan. En un primer momento abordamos algunas particularidades de la sociedad renacentista de la República de Venecia, la ciudad puerto y frontera, que recoge el anclaje al territorio que caracteriza la ciudad medieval y los entrecruzamientos que van moldeando las ciudades de la modernidad. Partimos de esta Venecia del Renacimiento pues tiene la doble condición de ser una ciudad de guetos y a la vez puerto entre Oriente y Occidente. Esta particularidad hace que Richard Sennett, en Carne y piedra. El cuerpo y la ciudad en la civilización occidental (2003), la escoja como una metáfora del paso de la sociedad medieval y renacentista hacia la modernidad. Luego, en un segundo momento, trabajamos el rasgo de la segregación y la exclusión entre los seres humanos a partir del gueto y los territorios, rasgo que acompaña la historia de la relación del hombre con las ciudades, pero que muta en el tiempo y según la configuración de las mismas. De esto último se desprende un tercer momento, en el cual intentamos una caracterización de las sociedades modernas y las manifestaciones artísticas, en la arquitectura, pero también en murales y grafitis, que dan cuenta de los procesos de desterritorialización y re-territorialización que tienen lugar en las ciudades que habitan las «culturas híbridas» (García Canclini, 1989), características de nuestras sociedades contemporáneas.

Este recorrido en tres momentos está atravesado por una tensión «entre la movilidad de la urbe y el enclavamiento en la tierra» (Moholy Nagy, 1970: 241). Este último, el enclavamiento o anclaje a la tierra está asociado a las ciudades medievales y renacentistas, mientras que la movilidad es característica de las ciudades modernas. Según Moholy Nagy, sin embargo, estos dos polos de la tensión se producen de forma sincrónica en la actualidad y en el medio 
de ambos está una zona intermedia conformada por las ciudades-satélite. En nuestro contexto latinoamericano, no se ha producido esta zona intermedia, sino una disolución de las fronteras de las ciudades, como veremos enseguida. Entretanto, para Sennett, estos dos polos son parte del proceso del paso hacia la modernidad, que libera el cuerpo de la tierra. El momento parece estar ubicado justamente en la Venecia renacentista, donde se produce el doble movimiento del fuerte anclaje del gueto y la liberación del ser humano que se sacude de las relaciones atávicas con el lugar y se mueve libremente.

\section{La muralla y la bisagra}

Venecia, durante los siglos XV y XVI, se había convertido en lugar de confluencia de muchas personas, un verdadero imán (Sennett, 2003: 234), lo que la hacía el puerto multicultural más importante de Italia. La comunidad cristiana tenía una relación compleja con las minorías que llegaban a asentarse al puerto, principalmente con los judíos. Los guetos cambiaron no sólo la arquitectura de la ciudad, sino sus ritmos y las lógicas comerciales. Sennett demuestra que debido al comercio y la vida misma de la ciudad, los venecianos necesitaban a los judíos, eran importantes para la economía local, pero no querían mezclarse con ellos. El gueto facilitaba la relación, podían interactuar con ellos pero por la noche el gueto se cerraba y quedaban aislados de la comunidad cristiana. También los alemanes eran ubicados en un lugar específico, el Fondaco dei Tedeschi, asimismo otras minorías como los griegos, los dálmatas o los armenios; sin embargo, la relación de los venecianos con los judíos era distinta a la que mantenían con las otras minorías, si bien la separación y la segregación era general. Dicha relación se matizaba por el hecho, según explica Sennett, de que cristianos y alemanes, por ejemplo, eran correligionarios. Asimismo, la ciudad que había dispuesto los lugares para esas minorías, fundó dos guetos judíos, que quedaban, al caer la noche, totalmente aislados de la ciudad, por muros y por agua, pues además de estar rodeados de murallas, estaban ubicados en islotes cuyos puentes se levaban todas las noches. El mar, que conectaba, también aislaba. Así de ambivalente era también la relación con los judíos, necesarios, deseados, pero también temidos, repudiados, aislados.

La batalla de Agnadello (1509), supuso un revés para la República de Venecia, la decadencia se le atribuyó a la corrupción moral que resultaba de la próspera actividad portuaria. La arremetida fue contra todo lo que podía suponer un placer sensual, desde la exuberante joyería con que se ataviaban las mujeres y los travestis hasta las especias que mejoraban el sabor de las comidas. Las prescripciones apuntaban a cubrir más el cuerpo y evitar el contacto, se llegó a creer que la sífilis se podía contagiar durmiendo con una prostituta o tocando el cuerpo de un judío. Lo que sucedió, en opinión de Sennett, es que tras la derrota el pueblo veneciano transfirió sus propias culpas a la población judía, una maniobra lamentablemente muy común. Al encontrar en la comunidad judía 
el origen de todos los desastres, surgió la necesidad de marcar el cuerpo. La separación ya no sólo era en la estructura física de la ciudad, sino en el vestido, para evitar el contacto aún en los momentos de encuentro. La marca postiza es necesaria para hacer la diferencia, pues la diferencia es, asimismo, ficticia. El color amarillo en el vestido, la muralla en las habitaciones.

El gueto se convirtió en el lugar de reclusión nocturno, pero era también el lugar que reportaba cierta seguridad a los judíos, en una época en que eran perseguidos, especialmente durante la cuaresma. Excepto algunos pogromos, en los que la turba invadía el gueto y arrasaba, quemaba y golpeaba, y cuando las enfermedades proliferaban en el encierro y el hacinamiento, los judíos se encontraban relativamente seguros en los guetos. Era diferente la situación de cortesanas y prostitutas, también excluidas, pues no contaban con refugios o reductos propios, la alternativa que tenían era mimetizar, confundirse entre los ciudadanos y hacerse pasar por una dama. Los guetos, en cambio, se convirtieron en unas pequeñas ciudades dentro de la ciudad, se permitía la construcción de sinagogas, por tanto no había necesidad de mimetizar, de fundirse con el otro; esa ventaja llevaba el veneno de un mayor aislamiento. El gueto, como anota Moholy Nagy, «no solamente era un lugar de humillación sino también un centro de orgullo e identificación» (1970: 251). Ambas comunidades, la judía y la cristiana, veían en ese aislamiento una virtud. La ligazón que existía entre los seres humanos y el lugar físico se acentúa.

Unos pocos años más tarde, en tierras americanas, la población africana esclavizada encuentra en los palenques los lugares para el enclave a la tierra, el reducto y refugio mínimo que podía caber en la diáspora. Al igual que el gueto, era aislamiento, algunos palenques «estaban localizados lo suficientemente cerca de las haciendas y los centros de la colonia» (Wade, 1997: 123). La relación es doble en este caso también de necesidad y deseo, pero también de exclusión. En ocasiones, como señala Nina de Friedemann, llegó a darse el comercio entre los palenques y algunas haciendas (1984: 80-84). Otro fenómeno en el contexto de la colonia fue el de los cabildos, que eran asociaciones de negros en las cuales con un permiso, casi como un salvoconducto, podían reunirse y llevar a cabo prácticas y celebraciones propias de sus culturas, siempre y cuando no implicaran levantamientos ni revueltas. Era una manera de ejercer el control sobre el Otro. Pero para la población negra fue un espacio de resistencia. De estos cabildos queda hoy el Cabildo Lumbalú de Palenque, que actúa en rituales funerarios y la Danza de los Congos en el Carnaval de Barranquilla (Wade, 1997: 126). En los ejemplos citados se presentan algunas semejanzas: primero, una ambigua relación con los otros, de necesidad y de exclusión, en el caso de los judíos en Venecia con fines comerciales y en el caso de los esclavos en la Colonia, con fines también comerciales, pero fundamentalmente de explotación. Segundo, para cada grupo social, en ambos casos, los enclaves terrestres supusieron la posibilidad de salvaguardar algunos aspectos de sus culturas, pero también cobraron el altísimo precio del aislamiento y la exclusión. Y tercero, 
estos enclaves eran lugares de identificación, por tanto su construcción (o mejor, su habitación-construcción), era construcción de la cultura.

Tanto Moholy Nagy como Sennett, aluden a El mercader de Venecia, de Shakespeare. La primera para probar esa doble condición del gueto como lugar de humillación, pero también de orgullo e identidad. Esta autora resalta las edificaciones que existieron al interior de los guetos de Polonia durante los siglos XVI y XVII, que le recordaban a los devotos «su destino de elección y su superioridad sobre la nación en que vivían» (1970: 251). Lo anterior aumentaba las barreras del doble aislamiento. Sennett, por su parte, apela al drama de Shakespeare para mostrar metafóricamente, en la hija de Shylock, el salto de la humanidad del anclaje de la tierra a la levedad y libertad de circulación. Sennett destaca el momento del drama, cuando Jessica, la hija de Shylock, decide renunciar a su identidad y anclaje al gueto y partir con su amado cristiano hacia la libertad, como el paso del enclave territorial a la movilidad de la Modernidad. Pero esta libertad moderna cobraba el precio de la pérdida de identidad y en buena medida de desarraigo. Cuando ese precio lo pagaron con creces los esclavos africanos en América, lograron algo de libertad justamente en la fundación de enclaves territoriales bajo la figura de los palenques, primeros pueblos libres de América desde la conquista.

Podríamos nosotros también aludir al drama de Shakespeare, particularmente a Shylock, cuyo monólogo en el tercer acto representa el espanto ante la exclusión y el rechazo, para sustentar el hecho de que justamente ante esas situaciones, el ser humano llega al límite de la deshumanización.

¿Y por qué razón?, ¿Porque soy judío?, ¿No tiene ojos el judío?, ¿No tiene manos el judío?, ¿No tiene órganos, miembros, sentidos, afectos y pasiones?, ¿No se nutre del mismo alimento, no se le hiere con las mismas armas, no está sujeto a las mismas dolencias, no se cura con los mismos remedios, no se calienta, no se hiela al calor y al frío del mismo verano y del mismo invierno que el cristiano? (1948: 48-49).

La pregunta remite a aquel grito de Antón de Montesinos en su Sermón de Adviento en 1511, cuando interpela a la sociedad divida: «Estos ¿No son hombres?, ¿No tienen ánimas racionales?». La misma exhortación inicia el testimonio de Primo Levi, sobreviviente de Auschwitz: "Considerad si es un hombre / quien trabaja en el fango / quien no conoce la paz / quien lucha por la mitad de un panecillo / quien muere por un sí o por un no. / Considerad si es una mujer / quien no tiene cabellos ni nombre / ni fuerzas para recordarlo / vacía la mirada y frío el regazo / como una rana invernal» (2002: 4).

Parece ser que es justamente en la escisión, la exclusión y la diferenciación forzada y artificial, que los individuos cuestionan su propia condición humana. Asimismo, el muro que separa, el puente que se leva para evitar el contacto, 
deshumaniza las relaciones en las ciudades, produce desencuentro, impide los cruces y la divide en cerrados enclaves que se fijan a la tierra.

Sobre la entrada de algunas ciudades de la baja Edad Media, se leía la siguiente inscripción: Stadt Luft macht frei; (Weber, 1987: 40), el aire de la ciudad hace libres, esto obedecía a que la emergente clase burguesa iba tomando el lugar del terrateniente feudal. La ciudad empezaba a perfilarse como un espacio de libertad que desprendía a los seres humanos del pesado anclaje de la tierra. Sin embargo, esta libertad se iba a empeñar enseguida a los designios del mercado. Los ciudadanos no gozaban de iguales privilegios y las clases sociales de los extramuros debían sentir, ante el letrero, un similar amargo dejo de ironía y crueldad al que sentían intramuros los prisioneros de Auschwitz cuando leían el letrero sobre la entrada del Lager, Arbeit match frei, el trabajo hace libres.

\section{Movilidad e individualismo}

A partir del siglo XIX los guetos ya han desaparecido, hasta su catastrófica reaparición durante el nazismo, sin embargo aunque fueron desapareciendo se mantuvo «el concepto de barrio separado» (Moholy Nagy, 1970: 251). La arquitectura de las ciudades permitió que los diversos grupos sociales se ligaran con un territorio, los barrios judíos, pero también los barrios obreros o los barrios estudiantiles, como el célebre Quartier Latin de París. Es en París justamente, durante este siglo, que tiene lugar un acontecimiento que determinará el destino de la ciudad moderna. Walter Benjamin sostiene que durante este siglo se tendió a «ennoblecer [las] necesidades técnicas haciendo de ellas finalidades artísticas» (1980: 187). La visión de Haussmann, el urbanista del París moderno, llevó a la construcción de grandes arterias interconectadas, los anchos bulevares suplantaron a las calles estrechas e intrincadas, lo cual, como nos hace notar Benjamin buscaba, bajo la idea de la modernización y el embellecimiento, imposibilitar la aparición de barricadas. Asimismo, el plan de Haussmann, llevó a una separación de las clases obreras y la burguesía, de los sitios de trabajo y los de recreo; con esto, ya no habría posibilidad de las barricadas y si llegaban a aparecer serían fácilmente controlables, así, la burguesía no participaría de las luchas obreras. La historia de la Comuna de 1871 demuestra que la planificación urbana, movida en apariencia por la modernización y la estética, sirve a los intereses del poder y el nuevo orden capitalista. El ejemplo de París fue rápidamente seguido por otras grandes capitales europeas.

En este proceso de modernización de las ciudades se parte de «la arquitectura como construcción de ingeniería. Sigue la reproducción de la naturaleza como fotografía», (Benjamin, 1980: 190). En París en el siglo XIX se produjeron dos espacios-umbral dentro de la ciudad: los panoramas y el pasaje comercial, antecesor de nuestros centros comerciales, zona umbral entre lo público y lo privado, así como el panorama es zona umbral entre la naturaleza y la 
urbanización, pues eran pasajes en los que se exponían fotografías que evocaban la naturaleza. Ambos espacios, que evocan las ruinas sobre la que se levanta la sociedad burguesa, son trabajados por Benjamin en sus Das Passagen-Werk o Libro de los pasajes. A pesar de las grandes avenidas que concibió Haussmann, la movilidad de la ciudad moderna, con sus arterias y anchas calles, sólo agudizó el individualismo del hombre moderno que se aislaba en medio de las multitudes. Las relaciones humanas estaban determinadas por esa nueva construcciónhabitación de la ciudad.

La libertad que prometía la sacudida del enclave territorial era el disfraz de otro amarre. Benjamin, justamente en «Panorama Imperial» de su obra Dirección única (1987: 27-36), manifiesta que el hombre pasó de estar atado a agrupaciones naturales, durante la Edad Media, a estar atado a una «comunidad antinatural». A esto se suma que lo autóctono pierde visibilidad bajo la nebulosa de lo indeterminado. «Con la ciudad ocurre lo mismo que con todas las cosas sometidas a un proceso irresistible de mezcla y contaminación: pierden su expresión esencial y lo ambiguo pasa a ocupar en ellas el lugar de lo auténtico» (Benjamin, 1987: 34). Las vías arterias, la movilidad urbana y ese reagrupamiento «antinatural», van perfilando un habitante de la ciudad que vive rodeado de la gran masa humana, pero encerrado en su individualidad. Esa gran masa humana que de lejos, como en el cuento de Poe, El hombre de la multitud, aparece como una unidad, múltiples relaciones entre todos aquellos elementos que componen la gran masa, pero que de cerca presenta individuos separados y sectorizados, como las ciudades modernas.

Las ciudades se constituían, entonces y a pesar de la promesa de libertad, bajo el signo constante de la segmentación y, como anota José Luis Romero para el caso latinoamericano, bajo el signo de la concentración del poder (2002: 372). La aparente libertad y movilidad de la ciudad moderna quedaba a merced de las lógicas del poder y, tal como en el cuento de Poe, la gran masa podía ser discernida a partir de las divisiones de los grupos sociales. Efectivamente así la ve el hombre que observa desde el Café, que es por cierto otro espacio umbral, en el que los individuos intentaban rescatar, aún con extraños, el arte de la conversación que según Benjamin, es otra de las grandes pérdidas que produce el individualismo moderno: «La libertad de la conversación se está perdiendo. Así como antes era obvio y natural interesarse por el interlocutor, ese interés se sustituye ahora por preguntas sobre el precio de sus zapatos o de su paraguas» (1987: 31).

En América Latina la segmentación se presenta de manera muy marcada, aunque no solamente, entre la ciudad y el campo, que operan como dos polos ideológicos. "Campo y ciudad son dos realidades diversas que parecen contraponerse y que, de hecho, muchas veces se han contrapuesto. Son distintos paisajes que alojan sociedades distintas y que han servido de fondo a procesos históricos distintos» (Romero, 2002: 336-337). En ese sentido, las tensiones se 
presentan entre la ciudad como núcleo y centro, y el campo como periferia. Pero las tensiones también son internas y cohabitan, dentro de las ciudades, diversos poderes, ya José Luis Romero nos aclara que se trata no sólo de concentración de poder institucional sino también no institucional. En términos de Ángel Rama, podríamos hablar de la «ciudad letrada» (1984), como el círculo más alto en las jerarquías del poder de la ciudad, sin que esto suponga que no existen tensiones entre los grupos de individuos letrados que lo conforman. La plaza principal de las ciudades latinoamericanas en general siguió el modelo de convocar, como si fuera en una especie de anillo selecto, en su marco al poder eclesiástico, civil y económico. La catedral, la alcaldía y las familias más prestantes habitaban ese primer anillo, y luego, como en círculos concéntricos, entre más cerca se estuviera de la plaza más estatus social se tenía. Pero entre los poderes que allí se movían no todo era armonía y alineamiento. La constitución de la ciudad moderna latinoamericana ha estado sujeta a estas tensiones internas y externas desde la Colonia.

\section{Hibridación y entrecruzamientos}

Las zonas umbral que en la ciudad moderna decimonónica estaban claramente ubicadas (el panorama, el pasaje comercial, el café), en América Latina toman otras formas y empiezan a copar mucho más espacio debido a los procesos de hibridación que han marcado la modernidad latinoamericana. El concepto de hibridación, que entra con fuerza en los estudios culturales a partir de la obra de García Canclini, Culturas híbridas. Estrategias para entrar y salir de la modernidad, es presentado en ésta como «un fenómeno indefectiblemente asociado a la modernidad»" (Gómez, 2009: 134), pues se incluye en el debate la lógica de mercado y las tecnologías masivas de difusión y consumo, asociadas a la «globalización de la cultura». Hemos sostenido anteriormente que la libertad que se ganaba al desprenderse de los lazos de la tierra se perdía enseguida en los propósitos del mercado, por tanto resulta fundamental que estos sean reconocidos como factor determinante de los procesos de las ciudades de la Modernidad. Asimismo, es ineludible el papel de la tecnología y los medios masivos de comunicación.

América Latina contemporánea es el resultado de yuxtaposiciones y entrecruzamientos y por ello sólo es posible comprender su modernidad desde la noción de culturas híbridas. "Así como no funciona la oposición abrupta entre lo tradicional y lo moderno, tampoco lo culto, lo popular y lo masivo están donde nos habituamos a encontrarlo» (García Canclini, 1989: 14). Es decir, que así como coexisten expresiones de lo tradicional y lo moderno, yuxtapuestas y entrecruzadas, también podemos ver que la participación de los ciudadanos es de forma intermitente, lo culto, lo popular y lo masivo (la industria cultural masiva) no se identifican ya con clases sociales o con territorios. Lo anterior supone una desterritorialización, o más bien una desnaturalización con el territorio, 
pues no quiere decir esto que el proceso quede en la liberación de los atavismos territoriales, sino que se presentan nuevas formas de territorialización. Asimismo, la condición intermitente de la participación de los individuos, en la nueva forma de la movilidad en las culturas que alcanzan procesos de hibridación. La hibridación no es sincretismo, pues este se refiere principalmente a procesos religiosos y sobretodo porque este puede remitir a la mezcla que conduce a un indeterminismo y a la ambigüedad de la que habla Benjamin en dirección única. Las culturas híbridas no son mezcla y sincretismo, sino más bien fragmentos y yuxtaposiciones.

Junto con estas particularidades, que corresponden a procesos de hibridación, según García Canclini, estaría además la aparición de lo que considera «géneros impuros». Se definen como aquellas prácticas culturales que se desvinculan de la colección patrimonial y logran la inserción de lo culto-popular, artesanalindustrial-masivo. No se trata de géneros híbridos en el sentido de un diálogo que se da cuando un artista o autor permite «abrir el territorio de la pintura o el texto para que su lenguaje migre y se mezcle con otros» (1989: 314), sino en que son géneros impuros en su misma constitución y éstos son, por excelencia, el grafiti y la historieta. Nos interesa particularmente para nuestro propósito el grafiti, como medio transcultural, que puede fusionar la palabra con la imagen y es frecuente que haya varios autores y temas en un solo muro, en lo que considera García Canclini «un ritmo fragmentado». El grafiti, para García Canclini, puede ser una «escritura territorial de la ciudad» (1989: 314), que da cuenta de la presencia y dominio en un sector de la ciudad, el ejemplo de este rasgo es el grafiti de los barrios marginales de Nueva York, que expresó «referencias de ghetto... incomprensible a veces para los que no manejaban ese código hermético» (1989: 315), así se daba un claro ejemplo de la delimitación, presencia y hasta «posesión» de un territorio. Esta manifestación, fragmentada y abierta a las intervenciones de varios autores (un grafiti puede ser respondido o contrariado en el mismo muro), el anonimato y a la vez la capacidad de «marcar» territorios, da cuenta de los procesos de hibridación cultural con los que comparten características. El grafiti posibilita también ciertas mezclas interculturales e intemporales con montajes que ironizan sobre la historia, es el caso de una silueta de Bolívar con cuernos y nariz de payaso, impresa en muros del centro de Bogotá, en plena efervescencia de las celebraciones del bicentenario.

La movilidad que posibilita la ciudad moderna se parece más a la libertad cuando se enmarca en procesos de hibridación y comunicación con los otros. Esa movilidad que nos permite, parafraseando el título de García Canclini, entrar y salir de la modernidad, que nos permite la re-localización y no el indeterminismo del desprendimiento del territorio. El reto es que estos procesos permitan suavizar la polarización entre las dos ciudades que parecen convivir dentro de la gran ciudad contemporánea latinoamericana, como sostiene Ana Cecilia Vallejo (2009:111), la «moderna, acorde con los procesos de globalización» y la de los marginados y segregados. 


\section{Referencias bibliográficas}

Aristóteles. 1982. Poética. Obras. Trad. Francisco de P. Samaranch. Madrid: Aguilar.

Bailey, P. 1854. Festus: a Poem. Boston: Benjamin B. Mussey. Disponible en: http:// books.google.com.co/booksid=dmOwt2Ej6EAC\&printsec=frontcover\&hl=es\#v=one page\&q\&f=false. Recuperado: 7 de junio de 2012.

Benjamin, W. 2002. The Arcades Project. Ed. Rolf Tiedeman. Trad. Howard Eiland y Kevin McLaughlin. Cambridge: Harvard University Press.

Benjamin, W.1987. Dirección única. Trad. Mercedes Allendesalazar. Madrid: Alfaguara.

Benjamin, W. 1980. Haussmann o las barricadas. Poesía y capitalismo. Iluminaciones. Tomo 2. Trad. Jesús Aguirre. Madrid: Taurus.

De Friedemann, N. 1984. Estudios de negros en la antropología colombiana. En Arocha, J. y De Friedemann, N. (editores). Un siglo de investigación social. Bogotá: Etno. 507562.

García, N. 1989. Culturas Hibridas. Estrategias para entrar y salir de la modernidad. México: Grijalbo.

Gómez, L. 2009. Hibridez. En: Mónica Szurmuk, y Robert McKee Irwin (eds.). Diccionario de estudios culturales latinoamericanos. México: Siglo XXI Editores e Instituto Mora.

Heidegger, M. 1997. Filosofía, ciencia y técnica. Santiago de Chile: Editorial Universitaria.

Heidegger, M. 1983. Interpretaciones sobre la poesía de Hölderlin. Barcelona: Editorial Ariel.

Levi, P 2002. Si esto es un hombre. Trad. Pilar Gómez Bedate. Barcelona: Muchnik editores.

Moholy-Nagy, S. 1970. Urbanismo y sociedad: historia ilustrada de la evolución de la ciudad. Barcelona: Blume.

Nedoshivin, G. 1970. La relación estética del hombre con la realidad. En Adolfo Sánchez Vázquez (Comp). Estética y marxismo. México: Ediciones Era. 137-148.

Pamuk, O. 2006. Estambul. Ciudad y recuerdos. Trad. Rafael Carpintero. Barcelona: Mondadori.

Poe, E. 2008. Cuentos completos. Trad. Julio Cortázar. Madrid: Páginas de espuma. 
Rama, A. 1984. La ciudad letrada. Hanover: Ediciones del Norte.

Romero, J. 2002. El obstinado rigor. Hacia una historia cultural de América Latina. México: Universidad Autónoma de México.

Rosano, L. 1986. La función de la poesía en Los raros de Rubén Darío. Revista de Crítica Literaria Latinoamericana, Año 12 (23): 117-125. Disponible en: http://www.jstor.org. biblioteca.uniandes.edu.co:8080/stable/4530249. Recuperado: 14 de agosto de 2012.

Sennett, R. 2003. Carne y piedra. El cuerpo y la ciudad en la civilización occidental. Trad. César Vidal. Madrid: Alianza editorial.

Shakespeare. 1948. Comedias. Buenos Aires: Clásicos Jackson.

Vallejo, A. 2009. Lo humano del espacio urbano: una aproximación del espacio urbano desde la antropología. Análisis: revista colombiana de humanidades. №. 74: 95-111.

Wade. P. 1997. Gente negra, nación mestiza. Bogotá: Ediciones Uniandes, Siglo del Hombre editores.

Weber, M. 1987. La ciudad. Trad. Julia Varela y Fernando Álvarez-Uría. Madrid: La Piqueta. 